\title{
Cuatro inscripciones pertenecientes al antiguo Convento de San Vicente de Villamayor de los Montes
}

\section{Alejandro García Morilla}

\section{(2) OpenEdition \\ Journals}

Edición electrónica

URL: http://journals.openedition.org/medievalista/410

DOI: 10.4000/medievalista.410

ISSN: 1646-740X

Editor

Instituto de Estudos Medievais - FCSH-UNL

Referencia electrónica

Alejandro García Morilla, «Cuatro inscripciones pertenecientes al antiguo Convento de San Vicente de Villamayor de los Montes », Medievalista [En línea], 14 | 2013, Puesto en línea el 01 julio 2013,

consultado el 19 abril 2019. URL : http://journals.openedition.org/medievalista/410 ; DOI : 10.4000/ medievalista.410 
Título: Cuatro inscripciones pertenecientes al antiguo Convento de San Vicente de Villamayor de los Montes

Autor(es): Alejandro García Morilla

Enquadramento Institucional: Instituto de Estudios Medievales - Universidade de León, Facultad de Filosofía y Letras (León, Espanha)

Contacto: agarm@unileon.es

Fonte: Medievalista [Em linha]. №14, (Julho - Dezembro 2013). Dir. José Mattoso.

Lisboa: IEM.

Disponível em: http://www2.fcsh.unl.pt/iem/medievalista/

ISSN: 1646-740X

\section{Resumo}

El conjunto epigráfico que hoy presentamos pertenece al primitivo monasterio de San Vicente de Villamayor de los Montes y se conserva en el claustro del actual templo cisterciense. Representa una fuente historiográfica de primer orden para la reconstrucción de su pasado histórico desde una perspectiva publicitaria y escrituraria. Este conjunto de cuatro inscripciones supone unos de los únicos vestigios conservados del primitivo cenobio de Villamayor.

Aquí analizamos este Corpus a través del método epigráfico moderno español empleado para la edición del Corpus Inscriptionum Hispaniae Mediaevalium, con el fin de presentar un estudio crítico y científico del conjunto que nos permita ahondar en las 
particularidades de esta actividad publicitaria - eso son las inscripciones -, de la finalidad que pudieron tener estos epígrafes; así como para un mejor conocimiento de la sociedad que las creó. Para ello abordaremos el estudio del proceso de génesis o elaboración de las inscripciones, el análisis de caracteres externos, internos y funcionales y nos detendremos también en la tradición epigráfica y la conservación.

Palavras-chave: Villamayor de los Montes, Epigrafía medieval, método científico, Paleografía, publicidad.

\section{Abstract}

The epigraphic group presented here belongs to the old monastery of St. Vicente de Villamayor de los Montes and is kept in the cloisters of the present Cistercian temple. It represents a primary historiographic source to rebuild its historical past from a scriptural and advertising perspective. This four-inscription group constitutes one of the few vestiges preserved from the early monastery of Villamayor.

Here we study this corpus through the modern Spanish epigraphic method used for the edition of the Corpus Inscriptionum Hispaniae Mediaevalium, in order to present a critical and scientific study of this group which could allow us to go deep into the particularities of this advertising activity - that is what inscriptions are - and the purpose which these epigraphs may have had, as well as for a better knowledge of the society which created them. To achieve that, we shall address the study of the genesis or elaboration of these inscriptions as well as the analysis of the outer, inner and functional characters, and dwell on the epigraphic tradition and its upkeep.

Keywords: Villamayor de los Montes, Medieval Epigraphy, scientific method, Palaeography, publicity. 


\title{
s
}

\section{Cuatro inscripciones pertenecientes al antiguo Convento de San Vicente de Villamayor de los Montes}

\author{
Alejandro García Morilla
}

Pocos o muy pocos son los datos que conocemos sobre el primitivo templo de San Vicente en Villamayor de los Montes. Los documentos conservados nos hablan de un monasterio existente, bajo la advocación de San Vicente, ya en el siglo XII ${ }^{1}$.

Casas Castells advierte que en sus orígenes debía ser una iglesia rural de clérigos más que un monasterio al uso $^{2}$. Se trataría pues, de un monasterio familiar con un reducido número de curas seculares encargados de las obligaciones pastorales de la zona ${ }^{3}$. Su consideración como monasterio tiene que ver con la independencia administrativa, económica y pastoral de que gozaba respecto al obispado ${ }^{4}$.

Como los vestigios conservados más representativos que son, hoy vamos analizar el conjunto de cuatro inscripciones funerarias pertenecientes a este primer periodo precisterciense. Se trata de los Epitaphia necrologica de Martín Díaz, del abad Juan, del abad Román y se cierta Urraca.

\footnotetext{
${ }^{1}$ CASAS CASTELLS, E. - "Orígenes, Fundación y Expansión de la Orden del Císter: el caso del monasterio de Villamayor". In AA. VV. - Jornadas Culturales con motivo del IX centenario de la Fundación del Císter: Monasterio de Villamayor de los Montes 1998, 29-30 de mayo de 1998. Burgos: Caja de Burgos, 1998, p. 35.

${ }^{2}$ Idem.

${ }^{3}$ PAGINAS - "Historia del Real Monasterio Cisterciense de Santa María la Real de Villamayor de los Montes". Cistercium. 23 (1952), p. 187.

${ }^{4}$ SERRANO, L. - El obispado de Burgos y Castilla primitiva desde el siglo V al XIII. Madrid: Instituto de Valencia de Don Juan, 1956, vol. II, p. 284.
} 
Estudiaremos este pequeño conjunto epigráfico a través del moderno método de análisis propuesto por los profs. García Lobo y Martín López que a su vez es el empleado en la edición del Corpus Inscriptionum Hispaniae Mediaevalium ${ }^{5}$.

\section{Génesis de las inscripciones:}

En el estudio de la génesis de las inscripciones se analizan todos los factores que condicionan la inscripción. Toda inscripción tiene por protagonistas al autor, al rogatario y al destinatario ${ }^{6}$. No suele resultar fácil conocer al autor de la inscripción ${ }^{7}$. Sin embargo, en muchas ocasiones contamos con medios para acercarnos lo más posible a él. En el caso de nuestra Colección, parece que éste pudo ser el abad. El propio sentido que tiene esta tipología epigráfica en relación a la "obligación que tenían las iglesias y monasterios de orar por sus deudos y benefactores" "8 así nos lo hace pensar.

Reconocido ya por todos que la finalidad de cualquier inscripción es publicitar un mensaje ${ }^{9}$, pensemos ahora en cual fue el motivo concreto que llevó a la elaboración de estos cuatro epígrafes. La respuesta está en lo que decíamos más arriba. Las comunidades religiosas ligadas a monasterios o iglesias tenían obligación de orar por su deudos o benefactores. Aquí también está la clave para conocer al destinatario de las inscripciones; la propia comunidad de San Vicente. Las inscripciones se encargarían de

\footnotetext{
${ }^{5}$ Se trata de los principios metodológicos expuestos por V. García Lobo y M $\mathrm{M}^{\mathrm{a}}$. E. Martín López en su manual, De Epigrafía Medieval. Introducción y álbum. León: Universidad de León, 1995, y que ha venido actualizándose hasta nuestros días a través de los numerosos trabajos del equipo del Corpus, dirigidos por el Dr. García Lobo.

${ }^{6}$ Para un conocimiento más exhaustivo de la génesis de las inscripciones remitimos a GARCÍA LOBO, V. y MARTÍN LÓPEZ, Mª. E. - De Epigrafia Medieval..., pp. 23-30.

${ }^{7}$ El prof. Barroca ya advierte que es posible averiguar quien es el autor de la inscripción aunque su presencia explícita no sea necesaria en la inscripción. Cf. BARROCA, M. J. - Epigrafía medieval portuguesa (862-1422). Vol. I, Oporto: Fundação Calouste Gulbenkian, 2000, p. 86.

${ }^{8}$ GARCÍA LOBO V. y MARTÍN LÓPEZ Mª . E. - De Epigrafia Medieval..., p. 39.

9 Entendemos por inscripción "cualquier testimonio escrito en orden a una publicidad universal y perdurable". Cf. GARCÍA LOBO, V. - Los medios de comunicación social en la Edad Media. La comunicación publicitaria. León: Universidad de León, 1991, p. 17. Esta definición está fundamentada en aquellas características dadas por el prof. Favreau al referirse a la Epigrafía medieval como la "sciencie de ce qui est écrit, en général sur une matière résistante, en vue d'une publicité universelle et durable”. Cf. FAVREAU, R. - "L’épigraphie médiévale". Cahiers de Civilisation Médiévale. Poitiers. XII Année, n. 4 (Octobre-Décembre 1969), p. 396.
} 
recordar a la comunidad las fechas en que debía prestarse especial atención a las oraciones por cada uno de sus miembros a modo de obituario ${ }^{10}$.

En relación al rogatario o autor material de la inscripción podemos decir que su presencia explícita en el texto no es habitual. Sin embargo, en uno de nuestros necrologios sí que aparece esta referencia. Se trata del correspondiente al abad Juan. En la última línea del texto aparece la firma del rogatario: Petrus fecit. Nos encontramos ante una fórmula habitual de suscripción en Epigrafía medieval ${ }^{11}$. No podemos asegurar que sea la misma persona la que ejecutó todo el conjunto. Sin embargo, tampoco es descabellado si se trató de una persona de especial relevancia dentro del scriptorium familiar o pequeño taller encargado de las necesidades epigráficas de su comunidad, donde no solía haber muchas manos profesionales para la realización de las diferentes tareas epigráficas $^{12}$.

Otro de los aspectos que nos permiten reconstruir la actividad del scriptorium es el análisis de las huellas que las tareas preparatorias de la inscripción o fases de la conscriptio $^{13}$ dejaron en el epígrafe. Dentro de ellas nos interesa sobremanera la impaginatio. En nuestra colección ésta varía de unas a otras. Así, por ejemplo, el epitafio de Martín Díaz, tiene una impaginación descuidada; las líneas no respetan horizontalidad alguna aunque el texto tiende a distribuirse uniformemente dentro de la caja de escritura. La inscripción carece de líneas de pautado así como de las de delimitación del campo de escritura. Sin embargo si busca cierta armonía en la extensión de las líneas como refleja el hecho de haber separado mucho los numerales de la data en la última línea para que finalice el renglón a la misma altura que los

\footnotetext{
${ }^{10}$ Esta idea fue puesta de manifiesto por el profesor García Lobo a propósito del conjunto de Epitaphia necrologica del claustro de Santo Domingo de Silos. Cf. GARCÍA LOBO, V. - "La epigrafía del claustro de Silos". In AA.VV. - El románico en Silos. IX centenario de la consagración de la iglesia y claustro (1088-1988). Burgos: Abadía de Silos-Universidad de Burgos, 1990, pp. 85-98.

${ }^{11}$ GARCÍA LOBO V. y MARTÍN LÓPEZ Ma . E. - De Epigrafia Medieval ..., p. 27.

${ }^{12}$ Sobre los talleres epigráficos remitimos al trabajo de MARTÍN LÓPEZ, M" . E. - "Centros escriptorios epigráficos de la provincia de Palencia". In AA.VV. - De Litteris, manuscriptis, inscriptionibus. Festcshrift zum 65. Geburtstag von Walter Koch, herausgegeben von Theo Kölzer, Franz-Albrecht Bornschlegel, Christian Frield, Georg Vogeler. Wien: 2007, pp. 203-227 y al nuestro propio, GARCÍA MORILLA, A. - "La escritura carolina publicitaria en la provincia de Burgos". Espacio, tiempo y forma. serie III (en prensa).

13 Sobre la conscriptio epigráfica y sus fases vid. con carácter general GARCÍA LOBO, V. - "La epigrafía medieval. Cuestiones de método". In AA. VV. - Centenario de la cátedra de "Epigrafía y Numismática” Universidad Complutense de Madrid 1990/01-2000/01. Madrid: Universidad Complutense de Madrid, 2001, pp. 92-96.
} 
anteriores. En el caso del necrologio del abad Juan, la impaginación fue más meticulosa. El campo de escritura fue delimitado con líneas incisas y aun se conservan restos de su impaginatio técnica ${ }^{14}$. En líneas generales, hay una buena separación de palabras y el conjunto goza de equilibrio. En cuanto al epitafio del abad Román vemos una inscripción mucho más tosca que la anterior, de aspecto general desordenado. La separación de palabras no es buena en los renglones centrales, las letras son de diferentes tamaños y las líneas no respetan los márgenes. Por último, el epitafio de Urraca es el que se trazó con más esmero, aunque tampoco hay una impaginación perfecta del epígrafe. La distribución del texto no es homogénea pero la separación de las palabras es correcta. Cuenta con lo que llamamos impaginatio estética, como reclamo publicitario ${ }^{15}$.

\section{Elementos materiales o caracteres externos}

Son aquellos aspectos que configuran externamente la inscripción; esto es, la materia escriptoria, la decoración, la técnica de ejecución ${ }^{16}$ y, sobre todo, la escritura. Buena parte de los aspectos aquí considerados son compartidos por todo el conjunto epigráfico.

14 Consideramos inscripciones con impaginatio técnica a aquellas "bien trazadas, regulares, con un módulo similar en sus letras y ajustadas a un espacio concreto matemático. Su aplicación es previa a la translitteratio donde se delimita, no solo el campo de escritura, sino el tamaño de las letras, su extensión y disposición geográfica, mediante la utilización del carbón o la tiza. También lo es su ejecución, normalmente con líneas suaves poco incisas, esgrafiadas con un stylus". Cf. GARCÍA MORILLA, A. "La impaginatio en las inscripciones del románico burgalés". In Impaginatio en las inscripciones medievales. León: Corpus Inscriptionum Hispaniae Mediaevalium, 2011, p. 219.

${ }^{15}$ Definíamos así a la inscripciones donde la impaginación cuenta con "una serie de líneas encargadas de organizar estéticamente el texto. Son referentes de lectura, de aproximación al lector. Acompañan al texto fortaleciendo el sentido público del objeto escrito... Tiene por misión captar la atención del lector, recordarle que es un escrito público y relevante que debe ser leído". Cf. GARCÍA MORILLA, A. - "La impaginatio", p. 218.

16 El estudio de las "huellas" dejadas en el epígrafe por las diferentes técnicas de ejecución son especialmente significativas por la información que pueden darnos acerca del proceso de elaboración de las inscripciones en el taller epigráfico. La técnica empleada para las inscripciones romanas ha sido especialmente trabajada por Susini. Cf. SUSINI, G. - Il lapicida romano. Introduzione all'epigrafia latina. Bolonia: Arti Grafiche Tamari, 1966, p. 35. Remitimos, también, para la epigrafía medieval a la obra de Favreau que dedica algunas líneas a las técnicas más habituales para la ejecución de epígrafes. Cf. FAVREAU, R. - Épigraphie médiévale. Turnhout: L’Atelier du Médiéviste, 5, 1997, pp. 51-52. De la misma manera ha sido estudiado para la epigrafía medieval portuguesa por Barroca. Cf. BARROCA, M. J., 2000, pp. 117-130. Para la epigrafía medieval española destacamos el estudio realizado por Rodríguez Suárez que amplía las técnicas empleadas en la Baja Edad Media. Cf. RODRÍGUEZ SUÁREZ, N. Inscripciones medievales de la provincia de Salamanca. León: (inédita), 2011, pp. 183-185.

Medievalista online № 14| Julho - Dezembro $2013 \odot$ IEM - Instituto de Estudos Medievais 6 www2.fcsh.unl.pt/iem/medievalista 
La materia escriptoria - la piedra- es el primero de ellos. No resulta raro si entendemos que el empleo de este material garantiza uno de los valores principales de toda inscripción: la permanencia. Qué duda cabe que su utilización está asociada a su durabilidad, aunque su elección tiene que ver, igualmente, con los criterios de funcionalidad ${ }^{17}$ y emplazamiento que se les iba a dar a nuestras inscripciones. En cuanto a la decoración, también es otro elemento común; en este caso por su ausencia. Ninguna de nuestras inscripciones tiene ningún elemento decorativo. Tan solo el cierto artificio con el que se han ejecutado algunas letras ofrecen un cierto valor estético a un conjunto ciertamente parco y sencillo. La técnica empleada para la ejecución de los epígrafes es el surco, entendido como el vaciado de material para imprimir el trazo de las letras. Es la más habitual en las inscripciones en piedra ${ }^{18}$. Este surco, cuando es trazado a bisel, aumenta los contrastes de luces y sobrar y con ello favorece la legibilidad de las inscripciones $^{19}$. Dentro de nuestro Corpus apreciamos ciertas diferencias en el necrologio del abad Román, donde el surco es más ancho y parece haberse realizado con un útil distinto al empleado en los otros tres.

Mención destacada merece la escritura. En líneas generales tenemos que decir que nos encontramos ante un alfabeto carolino, aunque con ciertas reminiscencias visigóticas en algunos caracteres como la $\mathbf{T}$ con bucle a la izquierda, la $\mathbf{A}$ sin trazo horizontal, la $\mathbf{N}$ con el trazo medio que tiende a la horizontalidad o la $\mathbf{O}$ próxima a formas romboidales. Todo esto en un marco cronológico comprendido entre 1143 y 1193, donde la evolución se refleja en el paulatino abandono de estas reminiscencias del periodo escriturario anterior. A continuación presentamos un cuadro de los alfabetos:

\footnotetext{
${ }^{17}$ La elección de una u otra materia escriptoria está ligada, en buena medida, a las características, tanto internas como externas, del texto. Robert Favreau ya insinúa esta idea cuando desglosa la gran variedad de materias escriptorias susceptibles de recibir una inscripción en función de la finalidad que se espera del objeto en sí. Cf. FAVREAU, R. - Épigraphie médiévale, pp. 47-51.

${ }^{18}$ Para todos los aspectos relacionado con la técnica, vid. con carácter general, GARCÍA LOBO, V. - "La escritura publicitaria en la Península Ibérica. Siglos X-XIII”. In AA.VV. - Inschrift und Material, Inschrift und Buchschrift (Fachtagung für mitteralterliche und neuzeitliche Epigraphik. Ingolstadt 1997). Munich: Bayersiche Akademie der Wissenschaften, 1999, pp. 12-15.

${ }^{19}$ GARCÍA LOBO, V. y MARTÍN LÓPEZ, Ma . E. - De Epigrafia Medieval..., p. 40.
} 


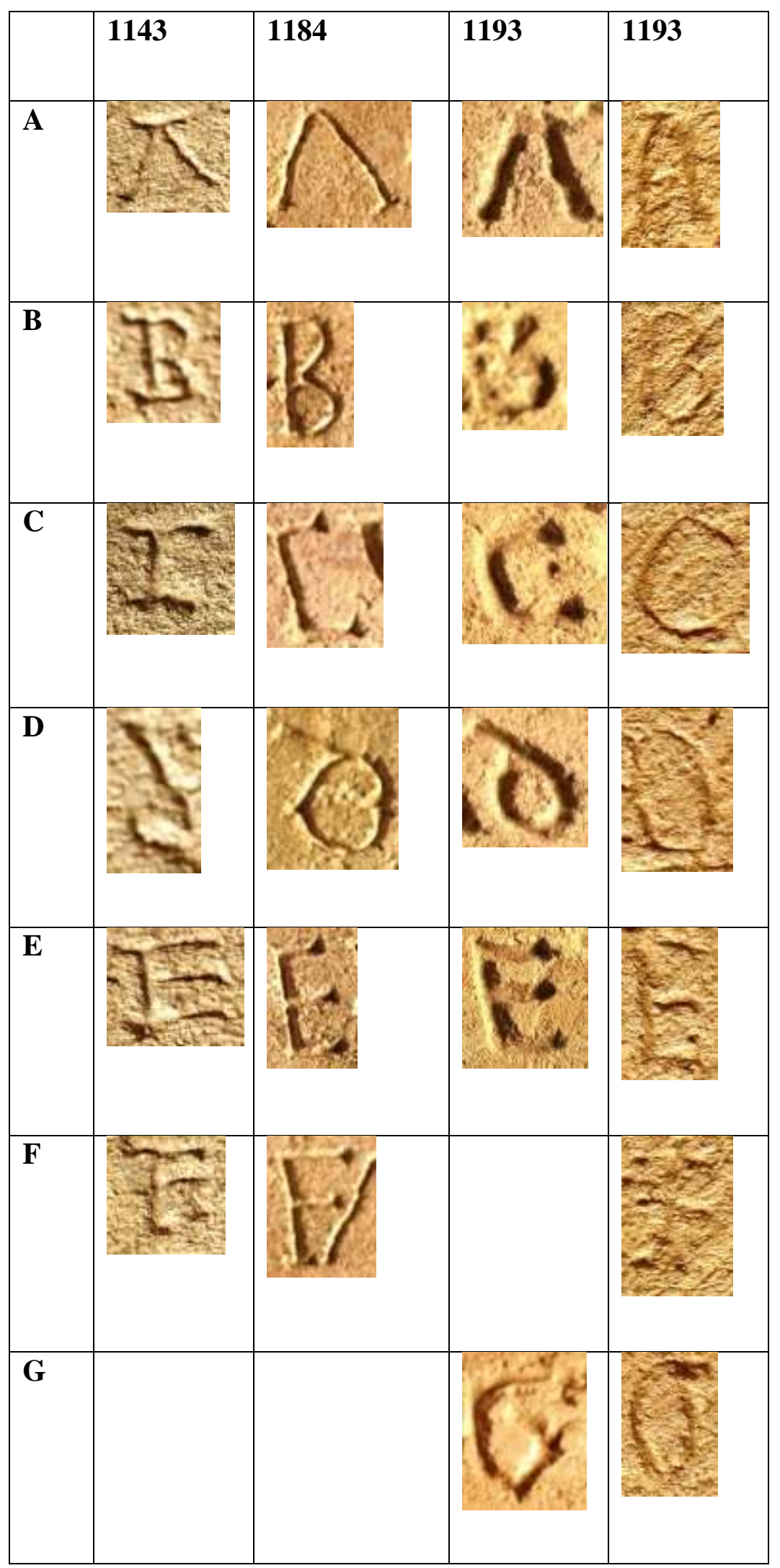




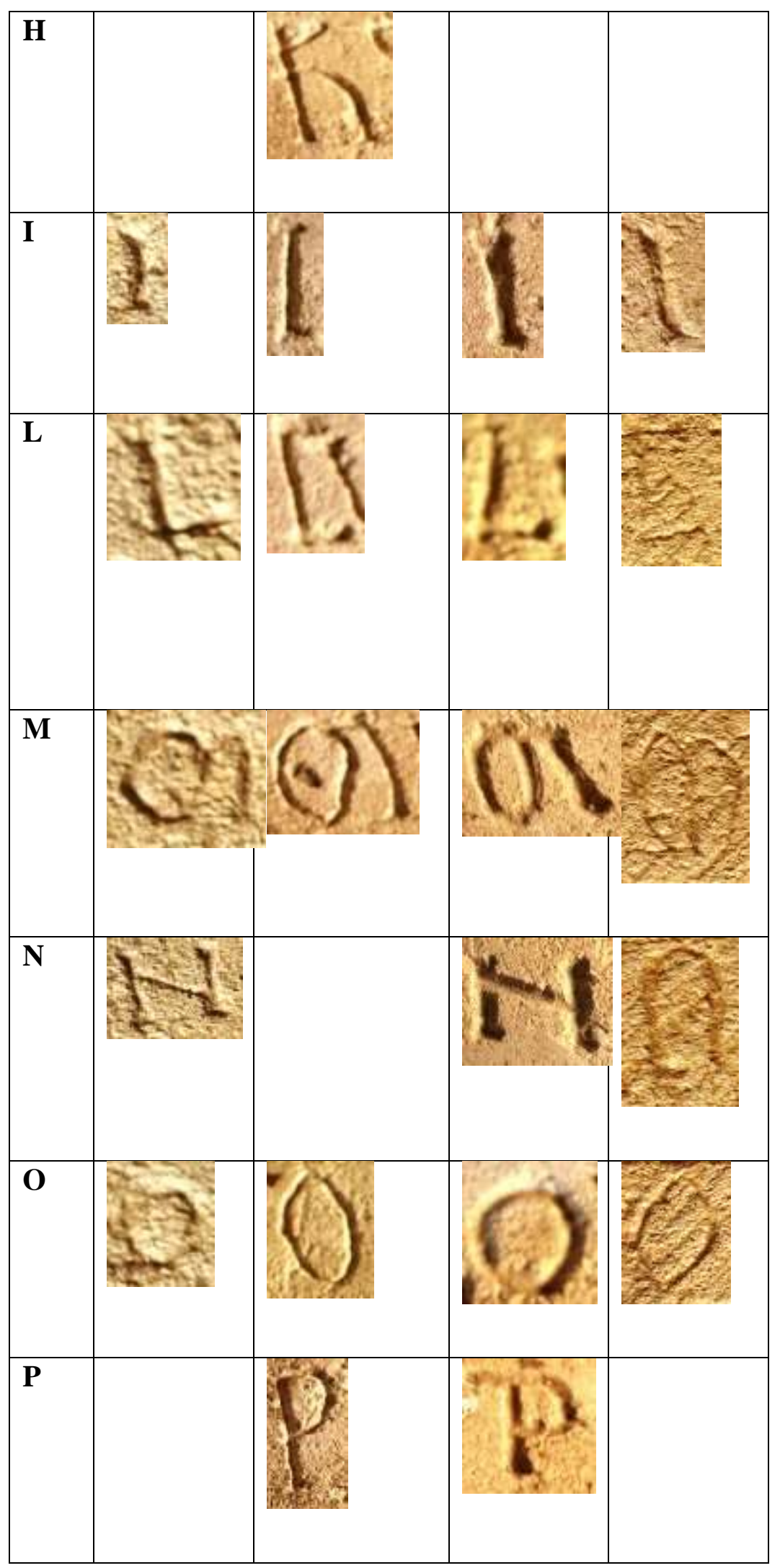




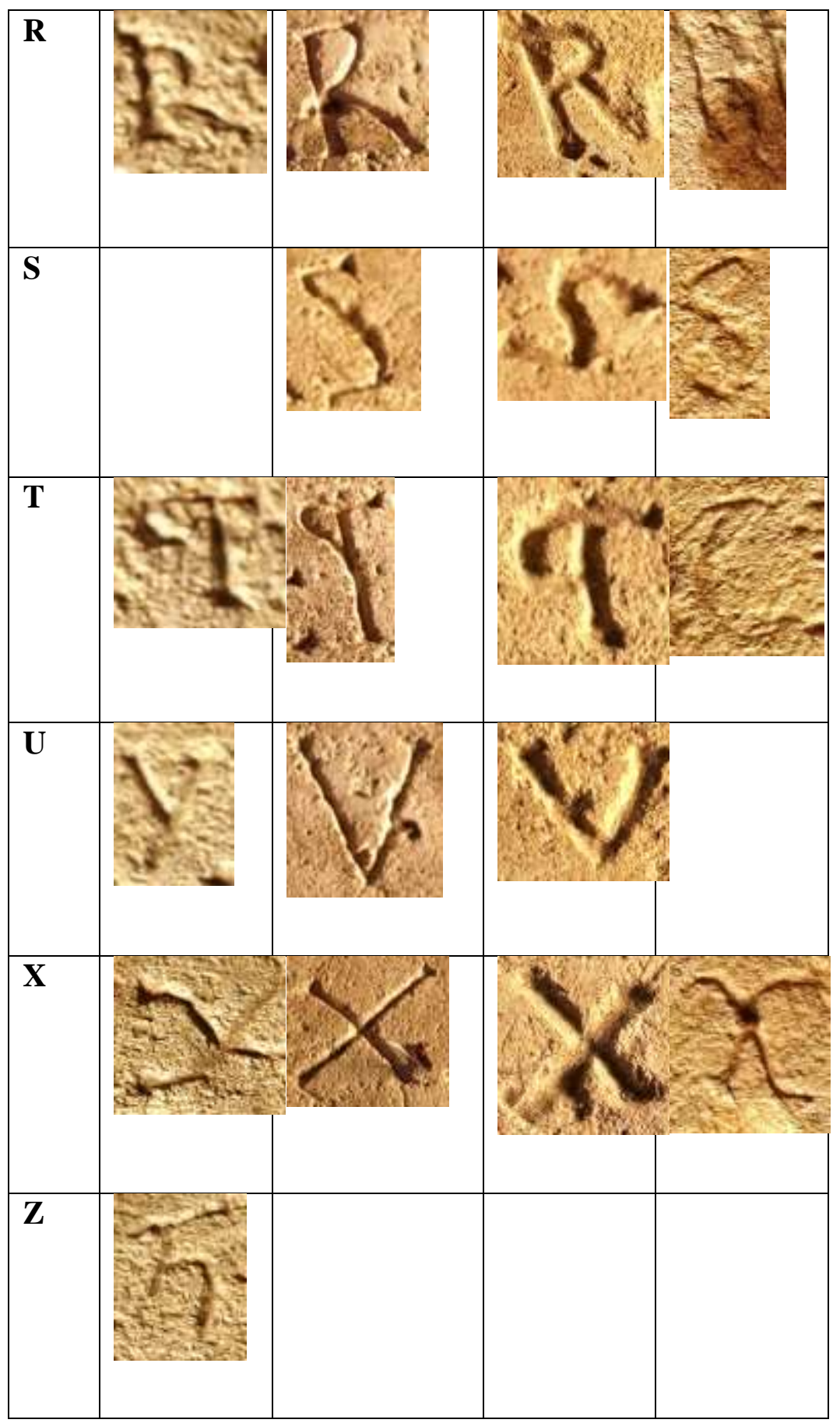

De este cuadro se desprenden una serie conclusiones especialmente relevantes: en primer lugar, la tardía influencia de la escritura visigótica ${ }^{20}$. A pesar de estar en un

${ }^{20}$ Hay que recordar que la escritura visigótica es la propia de la Península Ibérica y que su utilización en épocas tan tardías en esta zona responde, de forma genérica, a una actividad rural o puntual. Para un análisis más exhaustivo cf. GARCÍA MORILLA, A. - "La escritura visigótica publicitaria en la provincia de Burgos". Espacio, Tiempo y Forma, III, Historia medieval. 25 (2012), pp. 199-238. 
periodo plenamente carolino, el rogatario muestra preferencia por el empleo de una serie de grafías propias de la etapa escrituraria anterior. Esta preferencia se refleja normalmente en los mismos caracteres. Se trata, por tanto, de rogatarios formados y habituados a la escritura visigótica, pero buenos conocedores de la nueva escritura carolina; escritura a la que debían estar obligados a utilizar. Normalmente hemos asociado esta característica a los talleres rurales, a la actividad publicitaria local y puntual $^{21}$. Sin embargo, en el caso de Villamayor se trata de un aspecto más complejo. Por el dominio de la técnica, la evolución que presenta en pocos años y el artificio en determinados caracteres gráficos tenemos que pensar en un taller con cierta especialización o al menos de profesionales vinculados a un scriptorium librario y avezados en el empleo de la escritura publicitaria. Del empleo de caracteres visigóticos se desprende el gusto y la afinidad, al menos del maestro, con esta tradición escrituraria. Por contra, los discípulos tienden a evolucionar los caracteres a los hábitos y usos del momento, a pesar de conservar en buena medida esa tendencia del maestro. El mayor desarrollo queda reflejado en el epitafio de cierta Urraca de 1193. Rasgos bien ejecutados, escritura más esbelta y estilizada, cierto artificio en el remate de las letras, etc.

\section{Elementos formales o caracteres internos}

Son los relativos al texto: la naturaleza, la lengua y el estilo, las fórmulas y las tipologías $^{22}$. En cuanto a la naturaleza del texto diremos que se trata de inscripciones diplomáticas $^{23}$. Su lengua es la latina y el estilo, la prosa. Si analizamos las fórmulas del texto veremos que se trata de inscripciones asociadas a la muerte, que damos en

\footnotetext{
${ }^{21}$ Cf. nota anterior.

${ }^{22} \mathrm{Si}$ resulta ciertamente novedosa la clasificación tipológica de las inscripciones medievales no lo es en absoluto para la Epigrafía clásica. Cf. CAGNAT, R. - Cours d'Épigraphie latine. París: 1898, $4^{a}$ ed. París 1914. Roma: Anastasica, 1976, pp. 251-378.

${ }^{23}$ Entendemos por inscripciones diplomáticas "aquellas que recogen un hecho de naturaleza jurídica en sentido más o menos amplio" Cf. MARTÍN LÓPEZ, Mª E. y GARCÍA LOBO, V. - "La epigrafía medieval. Por una tipología de las inscripciones". In VIII Jornadas científicas sobre "documentación de la Hispania altomedieval (Ss. VI-X). Madrid: Área de Ciencias y Técnicas y Arqueología - Universidad Complutense de Madrid, 2010, pp. 185-214, concretamente, p. 190.
} 
clasificar como Funera ${ }^{24}$. Al fijarnos en la acción concreta de su verbo notificativo nos damos cuenta de que únicamente se nos da noticia del defunción. A estas inscripciones las denominamos Epitaphia necrologica. Su origen, insistimos, está en la tradición u obligación de las iglesias y monasterios de rezar por su deudos y benefactores.

\begin{tabular}{|l|l|}
\hline Inscripción & Verbo notificativo \\
\hline 1143 & Obiit \\
\hline 1184 & Obiit \\
\hline 1193 & Migravit \\
\hline 1193 & Obiit \\
\hline
\end{tabular}

Como vemos en el cuadro, en todos los epitafios menos en uno el verbo notificativo es obiit, el más habitual en esta tipología epigráfica. En el caso del necrologio del abad Román se emplea un giro más poético: migravit ad Christum. Sin embargo, la formulación no varía puesto que no ofrece dato alguno más que el óbito del difunto ${ }^{25}$. La utilización del verbo migravit nos vuelve a poner el relación con los scriptoria librarios ya que se trata de una formulación más propia de los elogios funerarios contenidos en algunos códices ${ }^{26}$.

\footnotetext{
${ }^{24}$ Ibidem, p. 191.

${ }^{25}$ Diferenciamos los epitafios necrológicos de los sepulcrales cuando tenemos noticia de la presencia del cuerpo del difunto en ese lugar. Esta noticia puede venir por la ubicación de la inscripción en la tapa o lateral del sepulcro o por una serie de fórmulas que así lo indiquen como: hic requiescit, hic iacet, etc. Cf. GARCÍA LOBO, V. y MARTÍN LÓPEZ. Ma. E. - De Epigrafia Medieval..., p. 39.

${ }^{26}$ El verbo migravit también aparece en otros epitafios de la provincia como el del abad Rodrigo de Silos. Suele tratarse de textos elaborados donde el formulario es fuertemente ampliado. Sobre el epitafio del abad Rodrigo, Cf. FLÓREZ, E. - España Sagrada. XXVII. Madrid: Oficina de Antonio Marín, 1772, pp. $472-476$.
} 


\section{Elementos o caracteres funcionales}

Son aquellos que confieren a la inscripción su especial carácter de medio de comunicación publicitaria. Tradicionalmente venimos hablando de tres: el emplazamiento, la legibilidad y la perdurabilidad. Sobre el primero de ellos poco o nada podemos decir. En la actualidad las cuatro inscripciones se encuentran situadas en cuatro sillares exentos en el claustro del monasterio de Villamayor. Tampoco contamos con datos certeros sobre su ubicación en el edificio primitivo ${ }^{27}$. A modo de hipótesis podemos plantearnos si su localización original fue el propio claustro del edificio primitivo al modo de Santo Domingo de Silos. Así -como en aquel caso- se trataría de letreros accesibles a la comunidad para ser leídos durante las oraciones rutinarias en el claustro $^{28}$. Esta idea no sería descabellada si asumimos que el culto a los difuntos es una de las primeras funciones de estas pequeñas comunidades y que favorecía el propio desarrollo del monasterio ${ }^{29}$.

En cuanto a la legibilidad de las cuatro inscripciones diremos que en líneas generales es buena. Gracias a la técnica utilizada -el surco trazado a bisel- la escritura mayúscula y el trabajo del espejo epigráfico el conjunto cumple con todos los requisitos para ofrecer una eficaz lectura. Únicamente se encuentran mutiladas parte de algunas letras que no presentan problemas para su restitución. Por lo que respecta a la perdurabilidad también podemos decir que es óptima. Tanto la elección del soporte -la piedra- como el emplazamiento -en el interior- y su recuperación en el proceso de restauración han permitido su permanencia.

\footnotetext{
${ }^{27}$ En nuestra visita al monasterio de Villamayor, una de las hermanas de la comunidad no informó de que se trataba de cuatro inscripciones aparecidas en uno de los procesos de restauración del actual cenobio y que durante años habían permanecido guardadas hasta su colocación en el claustro.

${ }^{28}$ Sobre este aspecto véase el caso de Silos. Cf. MARTín LÓPEZ, M". E. - "Las inscripciones medievales del monasterio de Santo Domingo de Silos". In AA.VV. - Silos. Un milenio. Actas del Congreso Internacional sobre la Abadía de Santo Domingo de Silos. Burgos: Universidad de Burgos, 2003, pp. 469-481, concretamente, pp. 480-481. Por su parte, Cecile Treffort, sobre la funcionalidad de estos Epitaphia necrologica y de las Intitulationes funerariae, habla de un hábito de buena memoria que se les profesa a los difuntos. Cf. TREFFORT, C. - L'Église carolingienne et la mort. Christianisme, rites funéraires et practiques commémoratives. Lyon: Presses Universitaires de Lyon, 1996, pp. 127-128.

${ }^{29}$ Cf. LINAGE CONDE, A. - Los orígenes del monacato benedictino en la Península Ibérica. I. León: Centro de Estudios e Investigación "San Isidoro", 1973, pp. 394-395.
} 


\section{Tradición epigráfica y conservación}

Es un aspecto novedoso incorporado a los estudios de Epigrafía medieval en España. Consiste en analizar en que forma han llegado los textos de las inscripciones a nosotros, clasificándolos en originales, copias o falsos. Para catalogar nuestro conjunto tenemos que volver sobre su tipología y ver el origen y sentido de estas inscripciones. García Lobo y Martín López consideran copias de obituario a todas los Epitaphia necrologica, ya que el origen de sus textos está, precisamente, en los libros de obituarios ${ }^{30}$. Así pues, uno de los abades del primitivo monasterio de San Vicente tomaría del libro obituario de su comunidad el nombre de dos abades y dos personajes ilustres ${ }^{31}$ con los que el monasterio tenía algún tipo de deuda o compromiso espiritual.

En cuanto a la conservación del conjunto epigráfico tenemos que decir que en líneas generales es bueno. Como decíamos más arriba, esta conservación ha dependido tanto de la adecuación en la elección del soporte como del emplazamiento de las mismas a lo largo de toda su vida. El deterioro que presentan algunos de sus caracteres parece deberse a las manipulaciones sufridas en los procesos de traslado y extracción de los viejos muros donde se encontrasen ubicadas.

${ }^{30}$ Cf. GARCÍA LOBO, V. y MARTÍN LÓPEZ, M․ E. - De Epigrafia Medieval..., p. 42

${ }^{31}$ Pensamos que se trata de dos personajes ilustres laicos por tratarse de una mujer y de un personaje con filiación paterna. No es habitual la presencia de mujeres en la epigrafía altomedieval a no ser que trate de personajes de alta alcurnia. Lo mismo sucede que con Martín Díaz, la presencia de un laico dentro del necrologio de una comunidad monástica pone de relieve su vinculación directa con el cenobio; normalmente como benefactor del mismo. 


\title{
APÉNDICE EPIGRÁFICO
}

\section{1}

1143, julio, 12

Epitaphium necrologicum del siervo de Dios Martín ${ }^{32}$.

A. VILLAMAYOR DE MONTES, Monasterio, Claustro, sillar exento (procedente del monasterio de San Vicente). Escr. visigótica y carolina de $2 \mathrm{~cm}$ x $4 \mathrm{~cm}$. No conserva líneas de pautado. Buen estado de conservación. Pieza de $21 \mathrm{~cm}$ x $34 \mathrm{~cm}$.

PUBL:

REF: Andrés Ordax, El monasterio de Villamayor de los Montes, p. 289 ${ }^{33}$; López Sobrino, Introducción, p. 19; Payo Hernanz, Evolución histórica de la escultura, p. 173.

\author{
I’ I I I I : ID9 IVLLII : OBIIT \\ a \\ FAMVLO D MARTIN \\ DIAZ IN E . R . A . M \\ $\mathrm{C} \cdot \mathrm{L} \cdot \mathrm{X} \cdot \mathrm{X} \cdot \mathrm{X} \cdot \mathrm{I}$
}

Quarto idus iulli, obiit famulo Dei Martin Diaz in Era millesima centesima optuagesima prima.

El día 12 de julio del año 1143 murió el siervo de Dios Martín Díaz.

\footnotetext{
32 Debido a la escasa documentación existente sobre el antiguo monasterio de Villamayor no hemos podido situar históricamente a los personajes. Andrés Ordax en su publicación advierte de la proximidad de la familia de este monasterio a los Lara.

${ }^{33}$ Andrés Ordax equivoca este epitafio con el desaparecido del abad Severino -perteneciente también al primitivo templo de San Vicente-, al no ser capaz de leer el cuerpo de la inscripción con la intitulatio del difunto.
} 
1184, febrero, 6

Epitaphium necrologicum del abad Juan.

A. VILLAMAYOR DE LOS MONTES, (procedente del antiguo monasterio de San Vicente) Claustro, sillar exento. Escr. carolina de $3 \mathrm{~cm} \times 1 \mathrm{~cm}$. No conserva líneas de pautado. Buen estado de conservación. Pieza de $24,5 \mathrm{~cm}$ x $28 \mathrm{~cm}$.

PUBL: Andrés Ordax, El monasterio cisterciense de Villamayor de los Montes, Burgos, p. 289.

REF: Payo Hernanz, Evolución histórica de la escultura, p. 173; López Sobrino, Introducción, p. 19.

\author{
+ VIII . IDS . FĒBŘII \\ OBIIT . FAMVLVS \\ DEI ABAS IOhS \\ SVB ERA : M . CC . \\ XXII . PETR9 . FECIT.
}

+ Octavo idus februarii obiit famulus Dei abbas Iohannes sub Era millesima 16ducentesima vigesima secunda. Petrus fecit.

+ El día 6 de febrero de 1184 murió el siervo de Dios Juan, abad. Lo hizo Pedro. 
1193, julio, 12

Epitaphium necrologicum del abad Román.

A. VILLAMAYOR DE LOS MONTES, Monasterio (Procedente del antiguo monasterio de San Vicente). Claustro, sillar exento. Escr. carolina mezclada con visigótica de $2 \mathrm{~cm} \times 1 \mathrm{~cm}$. No conserva líneas de pautado. Buen estado de conservación. Pieza de $24 \mathrm{~cm}$ x $22 \mathrm{~cm}$.

PUBL: Andrés Ordax, El monasterio cisterciense de Villamayor de los Montes, Burgos, p. $289^{34}$.

REF: Payo Hernanz, Evolución histórica de la escultura, p. 173; López Sobrino, Introducción, p. 19.

I .I .I. I. Id9 . IVLII .

$-{ }^{\mathrm{a}}-$
FMLO : DI : ABAS . RO

MANVS MIGR

AVIT Ad XPM

IN . ERA . M CC

a

XXX I :

${ }^{34}$ Andrés Ordax únicamente acierta a leer la data final del epitafio. 
Quarto idus iulii, famulo Dei Romanus migravit ad Christum in Era millesima ducentesima trigesima prima.

El día 12 de julio del año 1193 emigró hacia Cristo el siervo de Dios Román.

\section{4}

1193, agosto

Epitaphium necrologicum de cierta Urraca.

A. VILLAMAYOR DE LOS MONTES, Monasterio (procedente del antiguo monasterio de San Vicente), claustro, sillar exento. Escr. carolina de $3 \mathrm{~cm} \mathrm{x} 1,5 \mathrm{~cm}$. Conserva líneas de pautado. Buen estado de conservación. Pieza de $19 \mathrm{~cm}$ x $41 \mathrm{~cm}$.

PUBL:

REF: López Sobrino, Introducción, p. 19; Payo Hernanz, Evolución histórica de la escultura, p. 173.

OBIIT $\vdots$ FML $\vdots$ DEI $\vdots$ DNA

[V]RACA $\vdots$ MENSE $\vdots$ AĞO $\vdots$ ERA $\vdots$ M $\vdots$

$\vdots \mathrm{CC} \vdots \mathrm{XXX} \vdots \mathrm{I} \vdots$

Obiit famula Dei domina Uraca mense augusto Era millesima ducentesima trigesima prima.

Murió la sierva de Dios Urraca en el mes de agosto del año 1193. 


\section{CORPUS FOTOGRÁFICO}

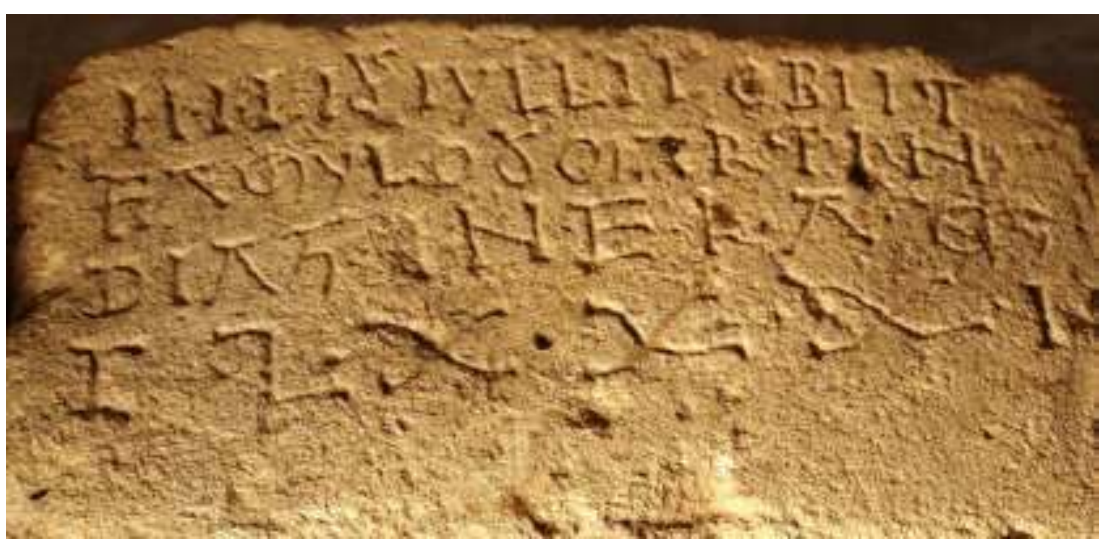

Fig.1. Epitaphium necrologicum de Martín Díaz. (García Morilla)

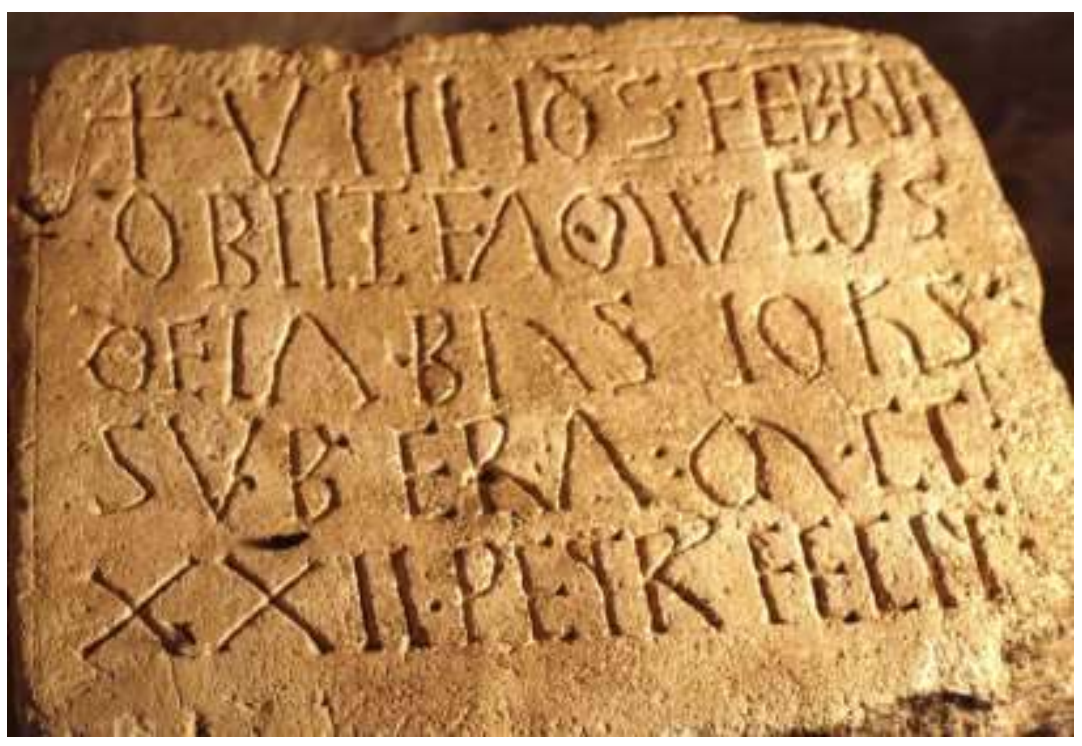

Fig. 2. Epitaphium necrologicum de abad Juan. (García Morilla) 


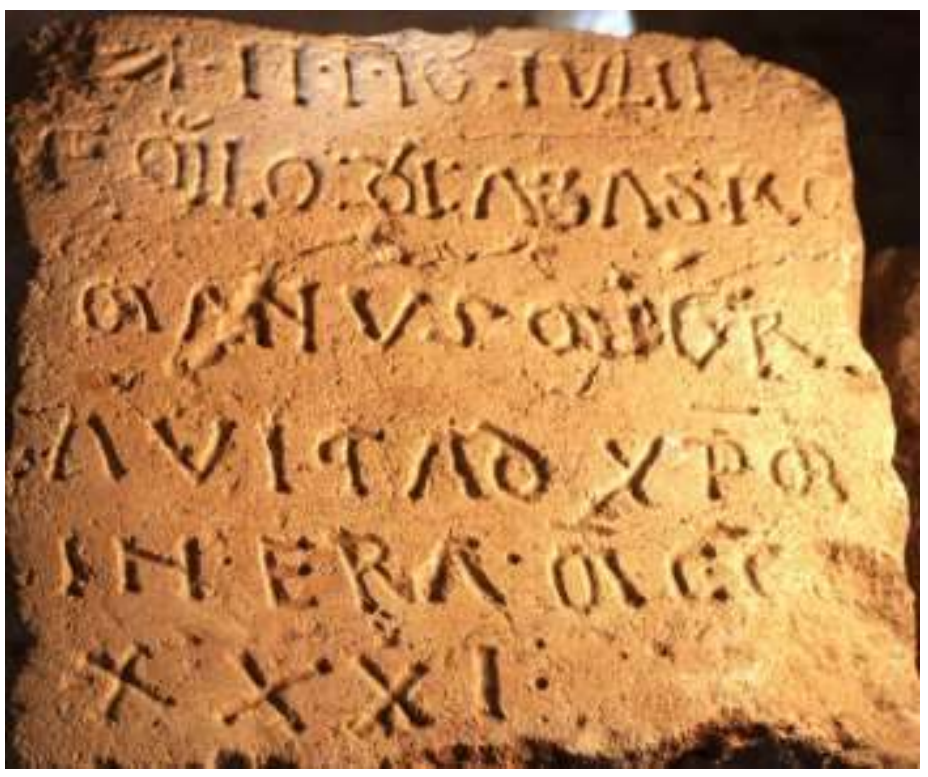

Fig. 3. Epitaphium necrologicum del abad Román. (García Morilla)

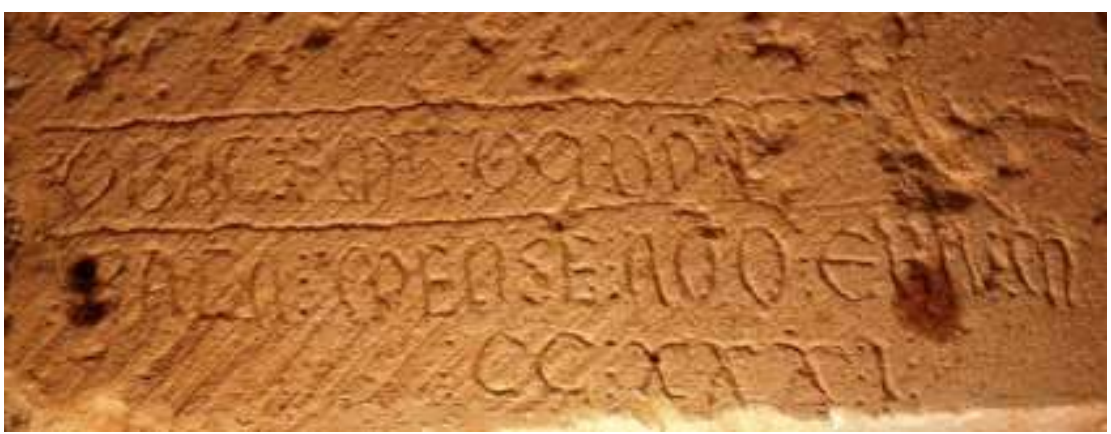

Fig. 4. Epitaphium necrologicum de cierta Urraca. (García Morilla)

Data recepção do artigo: 27 de Fevereiro de 2013

Data aceitação do artigo: 3 de Junho de 2013 


\section{COMO CITAR ESTE ARTIGO}

\section{Referência electrónica:}

GARCÍA MORILLA, Alejandro - "Cuatro inscripciones pertenecientes al antíguo Convento de San Vicente de Villamayor de los Montes”. Medievalista [Em linha]. Nº14, (Julho - Dezembro 2013). [Consultado dd.mm.aaaa]. Disponível em http://www2.fcsh.unl.pt/iem/medievalista/MEDIEVALISTA14/morilla1407.html.

ISSN 1646-740X.

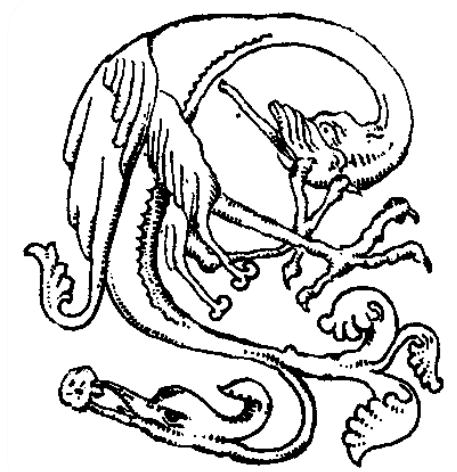

